\title{
PRODUÇÃO DE FLORES CORTADAS NO ESTADO DE MINAS GERAIS ${ }^{1}$
}

\author{
Production of cut flowers in the state o Minas Gerais \\ Paulo Roberto Correa Landgraf ${ }^{2}$, Patrícia Duarte de Oliveira Paiva ${ }^{3}$
}

\begin{abstract}
RESUMO
As flores de corte são importantes produtos da floricultura brasileira, as características da produção mineira são, no entanto, desconhecidas. Objetivou-se realizar um estudo da produção de flores de corte no estado de Minas Gerais, aplicou-se um questionário aos produtores do Estado, no período de 2003 a 2005. As visitas foram feitas in loco e os produtores foram identificados por meio de visitas nas áreas produtivas e os questionários foram respondidos por eles próprios. Analisando-se as respostas contidas nos questionários, identificou-se que a produção de flores de corte no estado de Minas Gerais é uma atividade realizada por 188 produtores, numa área plantada de aproximadamente 290,6836 ha As principais espécies cultivadas no Estado são: rosa (151,5710), sempre-vivas (57,26 ha), copo-de-leite (16,0255 ha), cravo (12,6290 ha) e helicônia (11,7600 ha). A produção é vendida para o todo o Brasil e também exportada para países da Europa, Ásia e América do Norte. Os principais produtos exportados são: rosas de corte, orquídeas de corte e sempre-vivas.
\end{abstract}

Termos para indexação: Floricultura, flores de corte, produção de flores.

\begin{abstract}
Cut flowers are important products of Brazilian floriculture. The characteristics of Minas Gerais production are, nevertheless, unknown. So, with the purpose of performing a study of the cut flower production in the state of Minas Gerais, a questionnaire was applied to flower growers of Minas Gerais state, in the period of 2003 to 2005. The visits were paid in loco and the growers were identified by means of visits to the flower-growing areas and the questionnaires were answered by them. By analyzing the answers contained in the questionnaires, it was identified that the cut flower production in the state of Minas Gerais is a business accomplished by 188 growers in a planted area of about 290.6836 ha. The main species grown in the state are: rose (151.5710 ha), sempre-vivas (57.26 ha), cala lilly flowers (16.0255 ha), carnation (12.6290 ha) and heliconia (11.7600 ha). The production is sold all over Brazil and it is also exported to countries of Europe, Asia and North America. The main exported produces are: cut roses, cut orchids and sempre-vivas.
\end{abstract}

Index terms: Floriculture, cut flower, flower production.

(Recebido em 4 de abril de 2006 e aprovado em 5 de julho de 2007)

\section{INTRODUÇÃO}

O consumo de flores e plantas ornamentais em todo mundo vem aumentando ao longo dos anos. Nos tradicionais países consumidores e nas novas economias de países em desenvolvimento, a demanda tem crescido significativamente. A produção e o consumo de flores e plantas ornamentais no Brasil vem acompanhando a tendência de expansão do mercado mundial, que também vem crescendo a cada ano. Avalia-se que a floricultura brasileira movimenta, no mercado interno, um valor global em torno de 750 milhões de dólares ao ano. Embora não seja um exportador tradicional de flores e plantas ornamentais, a profissionalização do segmento exportador no Brasil vem se intensificando nos últimos anos e, atualmente, o país já se projeta no cenário internacional como importante referencial de qualidade e competitividade (JUNQUEIRA \& PEETZ, 2002).

A atividade da produção de flores possibilita, segundo Bongers (1995), múltiplas formas de exploração e diversidade de cultivo que podem ser: produção de flores de corte, produção de flores e plantas envasadas, produção de folhagens, plantas de interior e viveiros de produção de mudas para jardins. As condições de produção do Brasil, dotado de diversidade de solo e clima, permitem o cultivo de grande número de espécies de comprovada qualidade e beleza. Os produtos nacionais como flores tropicais, bromélias, orquídeas, entre outros, têm estimulado novos mercados, sendo bastante competitivos no mercado mundial.

De acordo com Brackmann et al. (2005) o crisântemo de corte é uma das flores mais comercializadas devido à

\footnotetext{
'Parte da tese de doutorado do primeiro autor, apresentada ao curso de pós-graduação em Fitotecnia, Universidade Federal de Lavras/UFLA - Caixa Postal 3037 - 37200-000 - Lavras, MG

2Engenheiro Agrônomo, Professor - Universidade de Alfenas/UNIFENAS - 37130-000 - Alfenas, MG - paulo.landgraf@unifenas.br ${ }^{3}$ Engenheira Agrônoma, Professora - Departamento de Agricultura/DAG - Universidade Federal de Lavras/UFLA - Cx. P. 3037 - 37200-000 - Lavras, MG pdolivei@ufla.br
} 
grande diversidade de cores e formas de inflorescências, assim como pela resposta precisa ao fotoperíodo.

A distribuição varejista de flores, de acordo com Almeida \& Aki (1995), é realizada por meio dos seguintes canais: Floriculturas (55\%), Decoradores (20\%), Funerárias (10\%), Supermercados (8\%), Floras (5\%) e outras (2\%). As vendas de flores em supermercados cresceram muito rapidamente nas grandes cidades e os cash and carries estão se espalhando por todo o país.

No estado de Minas Gerais as principais regiões produtoras são: região de Barbacena; Sul de Minas, Munhoz e Araxá. No entanto, não existem dados recentes dessa atividade no estado de Minas Gerais. O último levantamento foi feito pela Associação Mineira de Floricultura (AMIFLOR, 1996) e somou informações com o estado do Espírito Santo, não gerando, em algumas situações, dados precisos. Não se tem dados exatos da produção de flores, em cada região do Estado, dificultando acesso à informações sobre a produção e comercialização desses produtos. As rosas são as principais flores de corte cultivadas no Brasil, concentrando 426 ha, seguidas por crisântemo com 234,5 ha, helicônias com 1001,8 ha, gérbera, gipsofila, estrelícias, tango, gladíolos e alpínias, entre outras 70 espécies (JUNQUEIRA \& PEETZ, 2005).

A floricultura de corte mineira tem nas rosas a sua exploração principal, havendo ainda destaque os cultivos de crisântemo, cravo, áster, gladíolo e produtos de floricultura silvestre. Entre as demais plantas ornamentais, destacam-se algumas mudas para jardim (azaléias, primaveras e dracenas, folhagens (aráceas), plantas envasadas (violeta africana e samambaia) e espécies arbóreas (bignoniáceas, melastomatáceas e leguminosas, principalmente). No total são comercialmente exploradas 120 diferentes plantas ornamentais (LANDGRAF \& PAIVA, 2005).

Dessa forma, há necessidade de se obterem informações referentes ao cultivo de flores de corte no estado de Minas Gerais, possibilitando um maior conhecimento do setor e situando melhor a floricultura mineira no âmbito nacional. Objetivou-se, no presente trabalho, estudar a produção de flores cortadas do estado de Minas Gerais.

\section{MATERIALE MÉTODOS}

O presente trabalho foi realizado no estado de Minas Gerais, que é constituído de 853 municípios e uma população de 17,5 milhões de habitantes, a segunda maior do Brasil, conforme dados do IBGE (2005). O estado de Minas Gerais está dividido em 10 macrorregiões de planejamento administrativo: Alto do Paranaíba, Central,
Centro-Oeste, Jequitinhonha/Mucuri, Norte, Noroeste, Vale do Rio Doce, Sul, Triângulo e Zona da Mata, que se caracterizam por aspectos econômicos e sociais distintos, ocupando áreas territoriais com dimensões e recursos diversificados (IBGE, 2005).

A produção de flores de corte foi diagnosticada por meio de um questionário, aplicado aos produtores das diferentes regiões do estado de Minas Gerais, no período de 2003 a 2005. As visitas foram feitas in loco nos 853 municípios, sendo identificado um total de 427 produtores. Os questionários foram respondidos pelos próprios produtores. As análises foram realizadas levando-se em consideração as respostas contidas nos questionários.

Para análise dos resultados utilizou-se estatística descritiva, por meio de tabelas de freqüência, além de análise estratificada conforme descreve Bussab \& Morettin (1987), de acordo com as diferentes macrorregiões de planejamento do estado de Minas Gerais.

\section{RESULTADOS E DISCUSSÃO}

Na Tabela 1, são apresentadas as porcentagens de produção de plantas para corte, cultivadas no estado de Minas Gerais.

No estado de Minas Gerais, as espécies mais produzidas são: rosas, sempre-vivas, copos-de-leite, cravos, helicônias e crisântemos. No Brasil, a espécie de corte mais produzida é a rosa, seguida da produção de crisântemo (JUNQUEIRA \& PEETZ, 2002).

Na região Central, onde está localizada a cidade de Barbacena, encontram-se 26 produtores de rosas, o que corresponde a $50 \%$ dos produtores do estado, seguido da região Sul onde estão $30,8 \%$ dos produtores (16 no total). A rosa exige para o cultivo clima ameno, e temperatura variando de $18^{\circ} \mathrm{C}$ a $25^{\circ} \mathrm{C}$ (BARBOSA et al., 2005), característico das áreas montanhosas das regiões Sul e Central de Minas Gerais.

Em Minas Gerais, o crisântemo é produzido principalmente nas regiões Sul e Central, havendo no total 15 produtores.

As sempre-vivas, importante espécie que compõe a listagem de exportação brasileira (NERI et al., 2005) é encontrada exclusivamente na região Central, especificamente na cidade de Diamantina, onde encontramse 07 produtores com manejo extrativistas (Tabela 2). Isso é conseqüência de sua origem: essas espécies são endêmicas dessa região (JOLY, 1970).

Algumas regiões apresentam pequena produção de flores de corte, como a região Noroeste, que possui exclusivamente a produção de lírio para corte. 


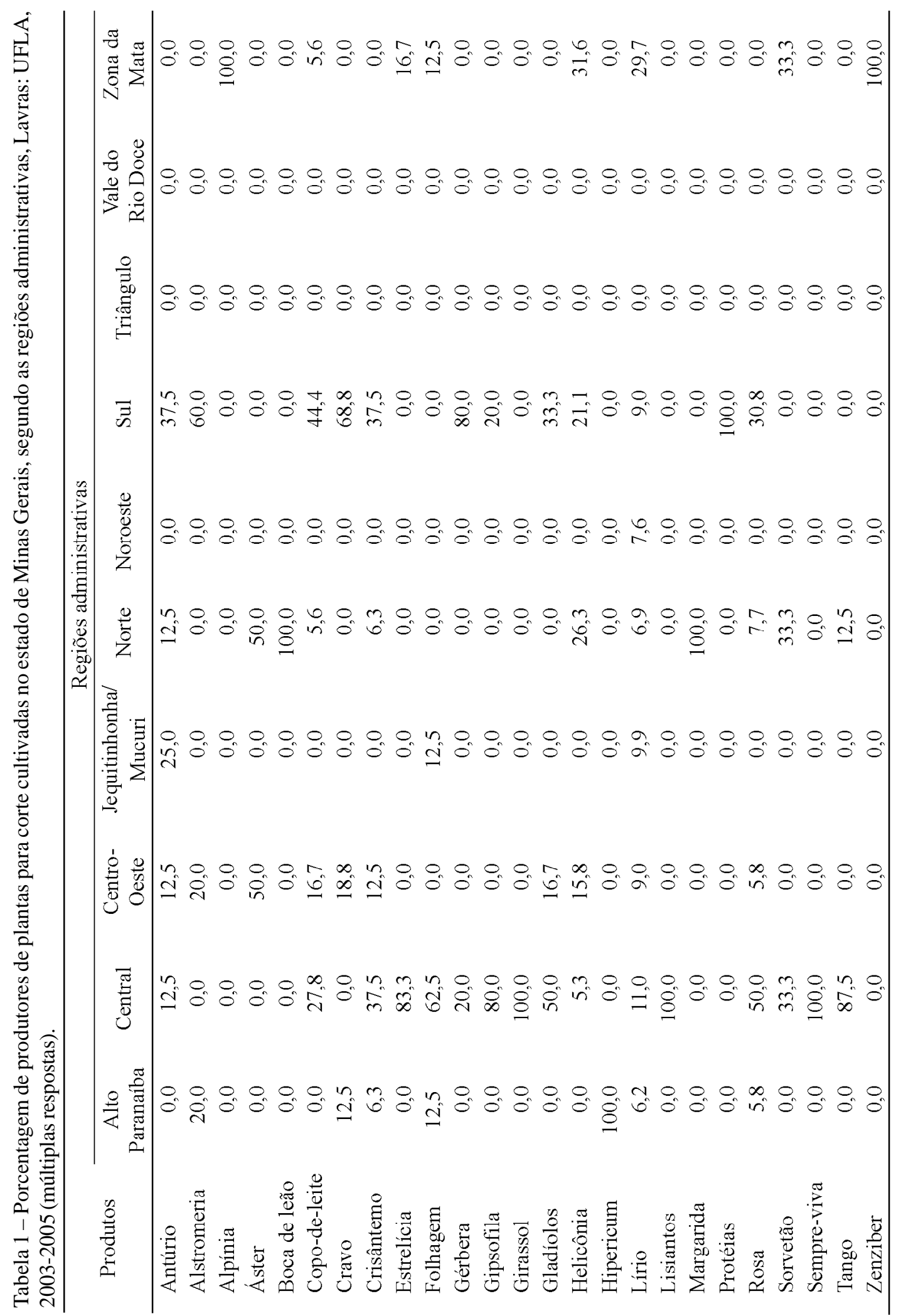

Ciênc. agrotec., Lavras, v. 33, n. 1, p. 120-126, jan./fev., 2009 


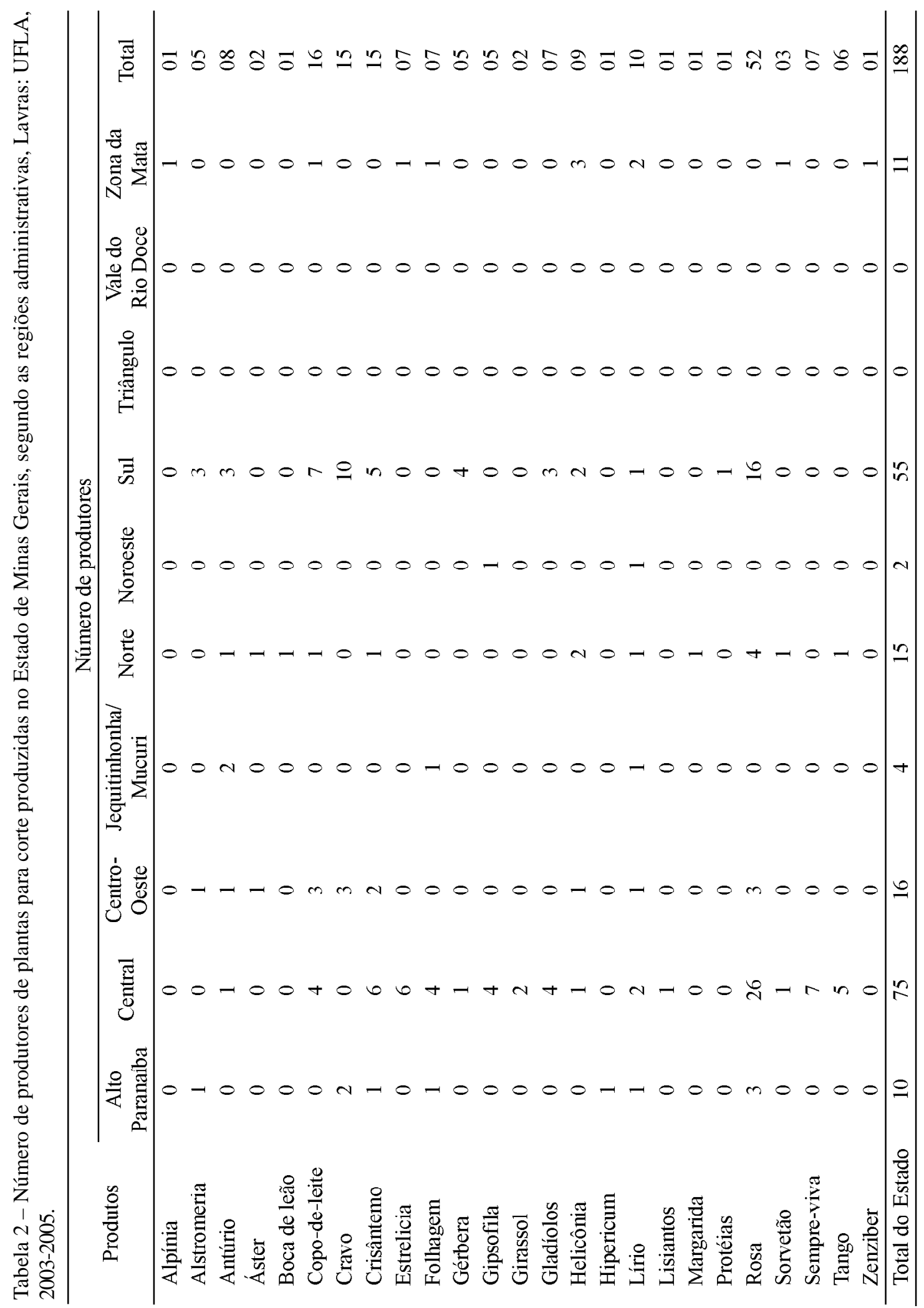

Ciênc. agrotec., Lavras, v. 33, n. 1, p. 120-126, jan./fev., 2009 
As flores tropicais apresentam características favoráveis à comercialização como beleza, exotismo, diversas cores e formas, resistência ao transporte, durabilidade pós-colheita, além de grande aceitação no mercado externo (LOGES et al., 2005). São produzidas em maior escala pela Zona da Mata. No município de Rio Casca destaca-se um produtor que, numa área de 8 hectares produz com qualidade helicônias, alpinías, estrelícia e zingiber, cuja produção é toda vendida para Belo Horizonte.

De acordo com Bezerra (1997), a floricultura tropical além de oferecer certa rentabilidade por área cultivada e com retorno econômico rápido utilizando pequenas áreas, gera emprego da ordem de 20 a 25 empregos/ha, entre diretos e indiretos. Porém é uma atividade especializada e requer técnicas modernas e mãode-obra qualificada.

$\mathrm{Na}$ região Central, a cidade de Sete Lagoas apresenta produção de plantas tropicais, como helicônias, estrelícia e sorvetão. A floricultura tropical é uma atividade que está em ascensão no Brasil e no mundo, por destacarse como um agronegócio gerador de renda, fixador de mãode-obra no campo e é adequado como cultura alternativa, para pequenos produtores (LINS \& COELHO, 2004). A temperatura ideal para o cultivo das tropicais é entre 22 a $25^{\circ} \mathrm{C}$. No Brasil, existem grandes plantações de flores tropicais, especialmente na região da mata úmida do Nordeste, com destaque para os estados de Pernambuco e Alagoas que já exportam suas flores para outros estados brasileiros (LAMAS, 2002). Por meio desse levantamento, observa-se que Minas Gerais também está atuando nesse segmento, tendo sido identificados 29 produtores, com produção de antúrio, alpínia, estrelícia, helicônia, sorvetão e zenziber.

A região Norte, devido ao clima, apresenta bom potencial para a produção de plantas cortadas como, por exemplo: crisântemo, helicônia, copo-de-leite, antúrio, gipsofila, lírio, margarida, boca de leão, áster e sorvetão.

O estado de Minas Gerais apresentou 188 produtores de plantas de corte, destacando-se a região Central com 75 produtores seguida da região Sul, com 55 produtores. As regiões Triângulo e Vale do Rio Doce não apresentaram produtores de plantas de corte.

Na Tabela 3, são apresentadas as áreas de cultivo, em ha, para as plantas ornamentais cultivadas no estado de Minas Gerais. No total, no Estado, são cultivados 1152,6046 ha com plantas ornamentais. No Brasil, o Ibraflor (2005) estima que sejam plantadas 5,2 mil ha com espécies ornamentais. Assim, Minas Gerais é responsável por 22,15\% desse total.

O tamanho médio estadual das áreas com flores oscilaram entre 0,8 ha e 6,3 ha no Espírito Santo e Goiás, respectivamente, enquanto os Estados do Rio de Janeiro (5,4 ha), Santa Catarina (5,2 ha), São Paulo (4,5 ha) e Pará (4,1 ha) apresentaram médias superiores em relação à média $(3,8$ ha $)$ das propriedades abrangidas pelo Levantamento Ibraflor (GRAZIANO, 2002).

Minas Gerais sempre foi caracterizada pela produção de rosas. Comparando-se com a área plantada de outros estados, verifica-se que São Paulo possui 426 ha (JUNQUEIRA \& PEETZ, 2004) e o estado do Ceará 15,9 ha (TOMÉ, 2004). Também em relação a essa cultura, a região Central, tradicionalmente, sempre foi considerada a maior produtora, no entanto, essa apresenta 49,11 ha plantadas com rosas e, em contrapartida, a região $\mathrm{Sul}$ apresenta 95,30 ha, quase o dobro da área. No Brasil, a área plantada de rosas é de 426 ha (JUNQUEIRA \& PEETZ, 2005). Assim Minas Gerais participa com 35,38\% dessa produção.

Entre as flores cortadas, a segunda espécie mais produzida é a sempre-viva, ocupando uma área de 57,26 ha, toda ela concentrada no município de Diamantina, na região Central.

No Brasil, a segunda flor de corte mais produzida são os crisântemos (ANTUNES, 2002) com 235 ha plantados (JUNQUEIRA \& PEETZ, 2005) que, no estado de Minas Gerais, ocupa a $6^{\mathrm{a}}$ posição, com relação à área plantada.

A produção de flores tropicais que tem apresentado relevante crescimento no Brasil nos últimos anos (LOGES et al., 2005) ocupa uma área de 19,70 ha em Minas Gerais e inclui a produção de alpínia, antúrio, estrelícia, helicônia, sorvetão e zenziber. 


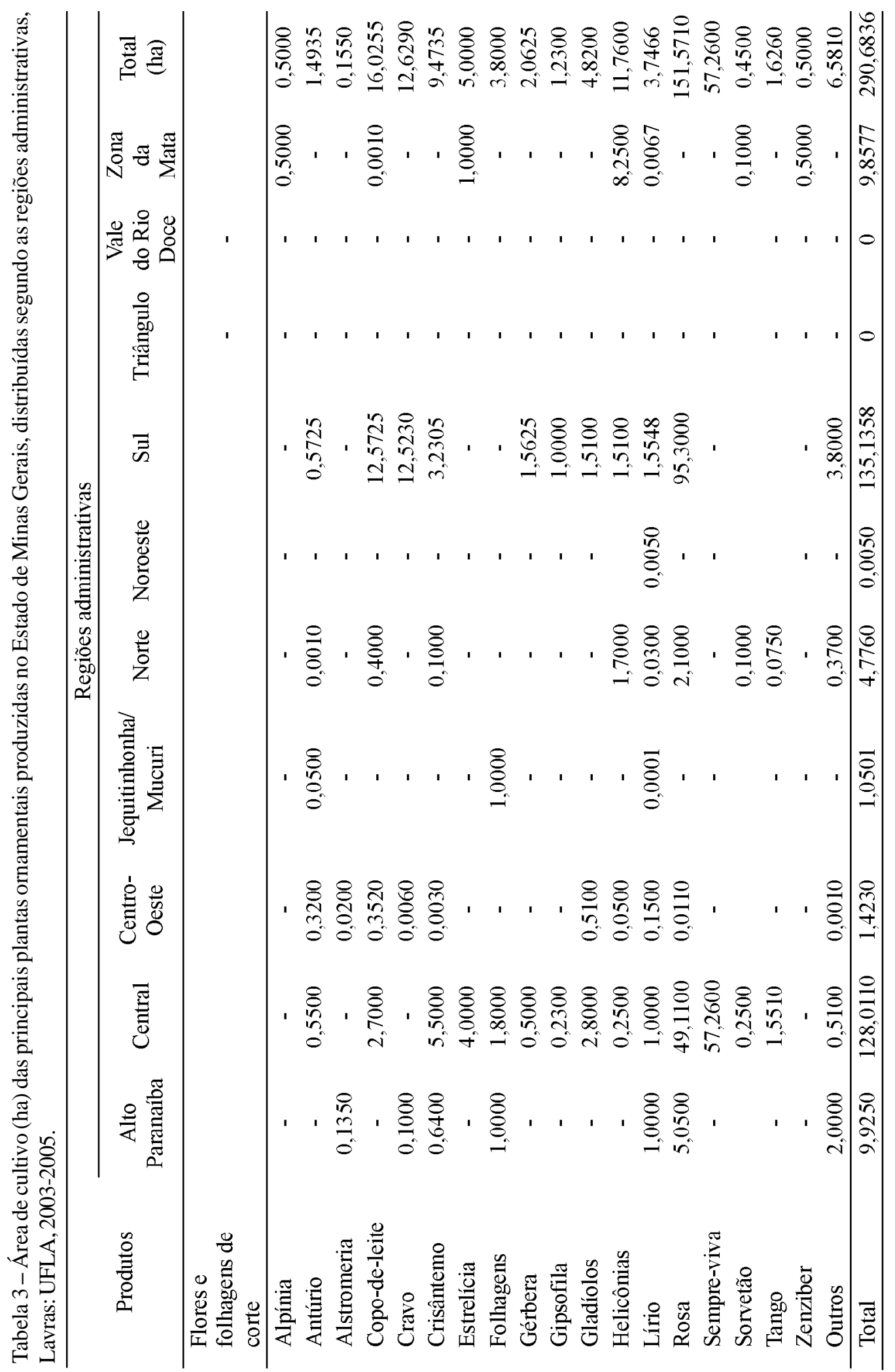

Ciênc. agrotec., Lavras, v. 33, n. 1, p. 120-126, jan./fev., 2009 


\section{CONCLUSÃO}

A partir dos resultados obtidos pelo estudo, podese concluir que a produção de flores de corte, no estado de Minas Gerais: é uma atividade realizada por 188 produtores, numa área plantada de aproximadamente 290,6836 ha. As principais espécies cultivadas no Estado são: rosa (151,5710 ha), sempre-vivas (57,26 ha), copo-deleite (16,0255 ha), cravo (12,6290 ha) e helicônia $(11,7600$ ha). A produção é vendida para o todo o Brasil e também exportada para países da Europa, Ásia e América do Norte. Os principais produtos exportados são: rosas de corte, orquídeas de corte e sempre-vivas.

\section{REFERÊNCIAS BIBLIOGRÁFICAS}

ALMEIDA, F. R. F.; AKI, A. Y. Grande crescimento no mercado das flores. Agroanalysis, Rio de Janeiro, v. 15, n. 9, p. 8-11, set. 1995 .

ANTUNES, M. G. Floricultura em Pernambuco. Recife: Sebrae-PE, 2002. 82 p. (Série Agronegócios).

ASSOCIAÇÃO MINEIRA DE FLORICULTURA. Cadastro da floricultura mineira e capixaba. Belo Horizonte, 1996. $153 \mathrm{p}$.

BARBOSA, J. G.; GROSSI, J. A. S.; PIVETTA, K. F. L.; FINGER, F. L.; SANTOS, J. M. Cultivo de rosas. Informe Agropecuário, Belo Horizonte, v. 26, n. 227, p. 20-29, 2005.

BEZERRA, F. C. Floricultura: aspectos gerais e técnicos de cultivo para flores tropicais. Fortaleza: Embrapa-CNPAT, 1997. 39 p. Apostila.

BONGERS, F. J. A economia das flores. Agroanalysis, Rio de Janeiro, v. 15, n. 9, p. 1-4, set. 1995.

BRACKMANN, A.; BELLE, R. A.; FREITAS, S. T.; MELLO, A. M. Qualidade pós-colheita de crisântemos (Dedranthema grandiflora) mantidos em soluções de ácido giberélico. Ciência Rural, Santa Maria, v. 35, n. 6, p. 14511455, nov./dez. 2005.

BUSSAB, W. O.; MORETTIN, P. A. Estatística básica: métodos quantitativos. 4. ed. São Paulo: Atual, 1987. 321 p.

GRAZIANO, J. da S. O que há de novo no rural brasileiro. Cadernos de Ciência e Tecnologia, Brasília, v. 19, n. 1, p. 37-67, jan./abr. 2002.
INSTITUTO BRASILEIRO DE GEOGRAFIA E ESTATÍSTICA. Dados populacionais municipais. Disponível em: 〈http://www.ibge.gov.br̀. Acesso em: 27 out. 2005 .

INSTITUTO BRASILEIRO DE FLORICULTURA. Encontro brasileiro de dirigentes de mercado de flores e plantas ornamentais. _ _ Disponível em: <http:// 'ceasacampinas.com.br/ibra.htm! . Acesso em: 12 jul. 2005.

JOLY, A. B. Conheça a vegetação brasileira. São Paulo: USP, 1970. $165 \mathrm{p}$

JUNQUEIRA, A. H.; PEETS, M. S. Os pólos de produção de flores e plantas ornamentais do Brasil: uma análise do potencial exportador. Revista Brasileira de Horticultura Ornamental, Campinas, v. 18, n. 1/2, p. 25-47, 2002.

JUNQUEIRA, A. H.; PEETS, M. S. Análise conjuntural das exportações de flores e plantas ornamentais no Brasil. Campinas: Unicamp, 2004.

JUNQUEIRA, A. H.; PEETS, M. S. Exportações brasileiras de flores e plantas ornamentais em 2005. [S.1.]: Hórtica Consultoria e Treinamento, 2005. 5 p.

LAMAS, A. M. Floricultura tropical: técnicas de cultivo. Recife: Sebrae-PE, 2002.

LANDGRAF, P. R. C.; PAIVA, P. D. de O. Produção e comercialização de flores em Minas Gerais. Informe Agropecuário, Belo Horizonte, v. 26, n. 227, p. 7-11, 2005.

LINS, S. R. O.; COELHO, R. S. B. Ocorrência de doenças em plantas ornamentais tropicais no Estado de Pernambuco. Fitopatologia Brasileira, Brasília, v. 29, n. 3, p. 332-335, maio/jun. 2004

LOGES, V.; TEIXEIRA, M. do C. F.; CASTRO, A. C. R. de; COSTA, A. S. da. Colheita, pós-colheita e embalagem de flores tropicais em Pernambuco. Horticultura Brasileira, Brasília, v. 23, n. 3, p. 699-702, jul./set. 2005.

NERI, F. C. S.; PAIVA, P. D. de O.; BORÉM, R. A. T. Produção e comercialização de sempre-vivas. Informe Agropecuário, Belo Horizonte, v. 26, n. 227, p. 56-61, 2005.

TOMÉ, L. M. Avaliação do desempenho logístico operacional de empresas no setor da floricultura: um estudo de caso no Ceará. 2004. 105 f. Dissertação (Mestrado em Engenharia dos Transportes) - Universidade Federal do Ceará, Fortaleza, 2004. 